\title{
Evaluation of Power Budget and Cell Coverage \\ Range in Cellular GSM System
}

\author{
Dr. S. A. Mawjoud \\ samialmawjoud 2005@yahoo.com
}

\begin{abstract}
The paper deals with study of affecting parameters on the communication performance and the coverage range of the cell, and thereafter on the efficient coverage of the intended area. The coverage starts within the basic unit (the cell), by estimating the affecting parameters on the signal power level in the uplink and downlink at the worst practical circumstances (the mobile station at the cell boundary, or in a high fading region), taking into consideration the factors causing fading and other losses is the signal power.
\end{abstract}

Keywords: Cellular system, Power Budget, cell range.

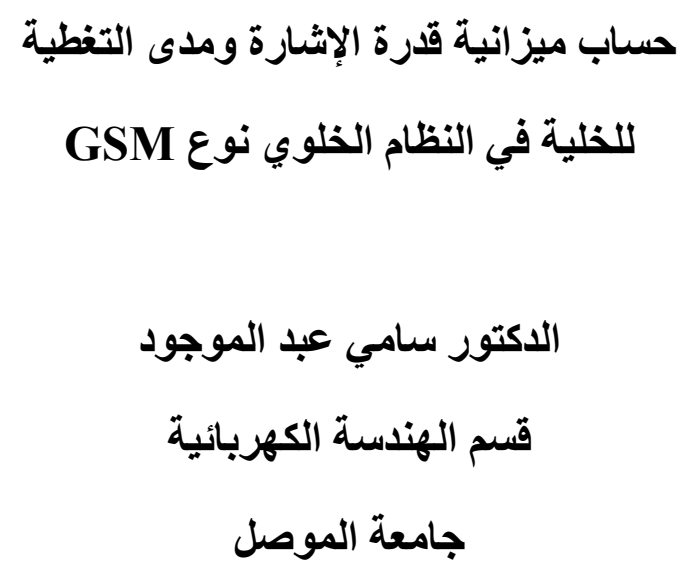

الخلاصة 


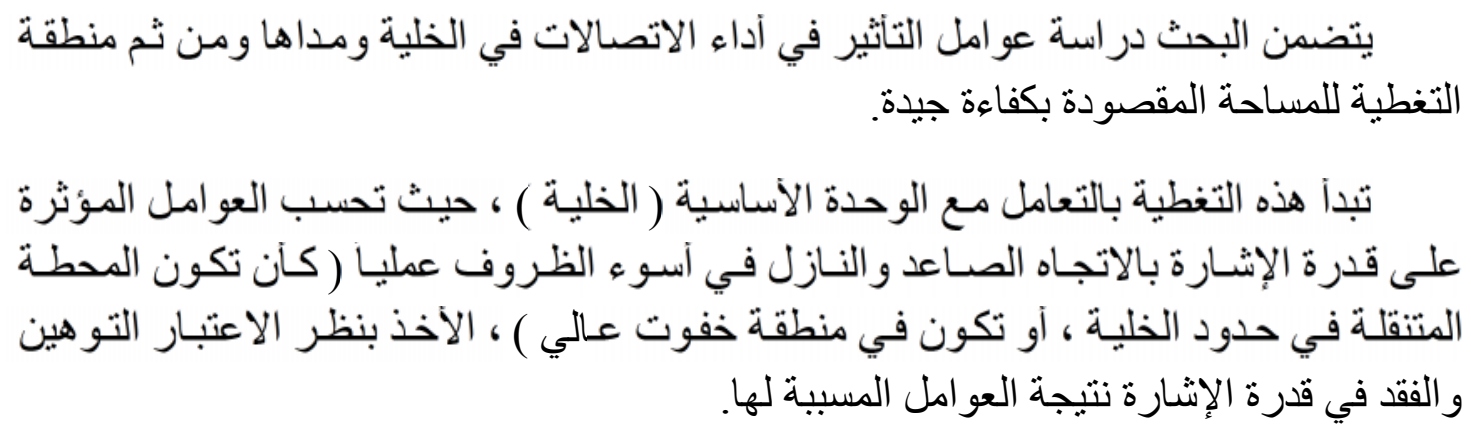

\section{Introduction [1-3]}

Received 10 Oct. 2006

Accepted 5 March 2007

The provision of wireless telephony network in a serving area requires planning and design in the most effective manner. The design involves determining the number of base stations and their locations to provide the necessary coverage in the serving area, meet the desired grade of service and satisfy the required traffic growth. In the design process the service providers generates a set of system requirements concerning the type of the desired system (e.g. Global system for Mobile Communication GSM, Code Division Multiple Access CDMA etc.), the expected traffic, and the desired service quality. In general received carrier to interference ratio $(\mathrm{C} / \mathrm{I})$, bit error rate $(\mathrm{BER})$ are used as the quality of the services indicator.

According to the above requirements, an appropriate propagation model is used for the link budget calculation and hence the maximum affordable path loss for a given transmitter power so that the $\mathrm{C} / \mathrm{I}$ at any point in the intended servicing area is sufficient to ensure the desired quality.

One of the design objectives is to provide coverage on the entire serving area with a minimum number of base stations consistent with the requirement of the projected traffic growth. 
For satisfactory service, the system should be designed so that the mobile stations (MSs) receive a sufficiently strong signal inside buildings or vehicles where the penetration loss is significant, outside buildings where there is no such penetration loss, and on highways. The system may then be designed so as to optimize one of the following parameters or any combination thereof:

- The signal distribution as received by mobiles or base stations.

- The C/I ratio at base station.

- The C/I ratio at mobile station or any combination of these parameters.

However the usual practice is to design the system such that both the down link and the uplink have a balanced signal distribution.

\section{Propagation Mechanisms [4][5]}

Electromagnetic waves when propagating suffer form several effects that results in power loss, these effects are:

- Scattering: When objects are smaller than the wavelength of the propagating wave (e.g. foliage, street signs, lamp posts), the incoming wave is scattered into several weaker outgoing signals.

- Reflection: Propagating wave impinges on the object that is larger as compared to wavelength (e.g. the surface of the earth, tall buildings, large walls, etc.).

- Diffraction: Diffraction allows propagating waves to propagate around the curved surface of earth and behind obstruction producing Fresnel Zone (shadow region). Scattering and diffraction result in small-scale fading while reflection results in large scale fading.

\section{Path Loss Prediction Models [4][5][6][7]}

The most commonly used path loss models are:

(a) Okumura Model: Okumura developed an empirical model that is derived from extensive radio propagation studies in Tokyo. It is represented by means of curves with which is applicable for urban areas. For other terrain, Okumura has provided correction factors for three types of terrain:

- Open Area: Corresponds to a rural, desert type of terrain: 
- Quasi Open area: Corresponds to rural, countryside kind of terrain.

- Suburban area.

(b) Hata Model: The model is an empirical formulation of the graphical path loss data provided by Okumura. Hata presented the urban area propagation loss as a standard formula and supplied correction equations for other types of areas.

- Urban Area:

$$
\begin{aligned}
\text { Lpu }= & 69.55+26.16 \log _{10} f-13.82 \log _{10} h(t)-a h(r) \\
& +\left[44.9-6.55 \log _{10} h(t)\right] \log _{10} d
\end{aligned}
$$

Where:

$\mathrm{L}_{\mathrm{pu}}=$ Propagation loss in urban area $(\mathrm{dB})$

$\mathrm{f}=$ The carrier frequency $(150 \mathrm{MHz} \sim 1500 \mathrm{MHz})$

$h(t)=$ Base station antenna height $(20-200 \mathrm{~m})$

$h(r)=$ Mobile station antenna height $(1 \mathrm{~m} \rightarrow 10 \mathrm{~m})$

$\mathrm{d}=$ Distance $(1 \mathrm{~m} \rightarrow 20 \mathrm{Km})$

- For small to medium city:

$$
\mathrm{ah}(\mathrm{r})=\left(1.1 \log _{10} \mathrm{f}-0.7\right) \mathrm{h}(\mathrm{r})-\left(1.56 \log _{10} \mathrm{f}-0.8\right) \quad(\mathrm{dB})
$$

- For large city:

$$
\mathrm{ah}(\mathrm{r})=3.2\left[\log _{10}(11.75 \mathrm{~h}(\mathrm{r}))\right]-4.97 \quad(\mathrm{~dB})
$$

Where $\mathrm{ah}(\mathrm{r})$ is a correction factor.

- Suburban area, the standard Hata formula in equation (1) is modified as:

$$
\text { Lps }=\text { Lpu }-2\left[\log _{10} \frac{\mathrm{f}}{28}\right]^{2}-5.4
$$

Where Lps $=$ path loss $(\mathrm{dB})$ in suburban area.

- Open Area: equation (1) is modified to:

$$
\text { Lpo }=\text { Lpu }-4.78\left[\log _{10} \mathrm{f}\right]^{2}+18.33 \log _{10} \mathrm{f}-40.94
$$

Where Lpo $=$ path loss $(\mathrm{dB})$ in open area 
Based on urban macrocell [4][5] for GSM 900:

$\mathrm{f}=900 \mathrm{MHz}, \mathrm{h}(\mathrm{t})=30 \mathrm{~m}, \mathrm{~h}(\mathrm{r})=1.5 \mathrm{~m}$.

Equation (2) and (3) are negligible here.

The path loss for urban, suburband and open areas using equations 1, 4 and 5 are plotted as a function of cell radius as shown in figure (1).

Figure (2) is a plot of urban area path loss as a function of cell radius, $\mathrm{f}=900 \mathrm{MHz}, \mathrm{h}(\mathrm{r})=1.5$ and $\mathrm{h}(\mathrm{t})$ varied from $30 \mathrm{~m}$ to $100 \mathrm{~m}$.

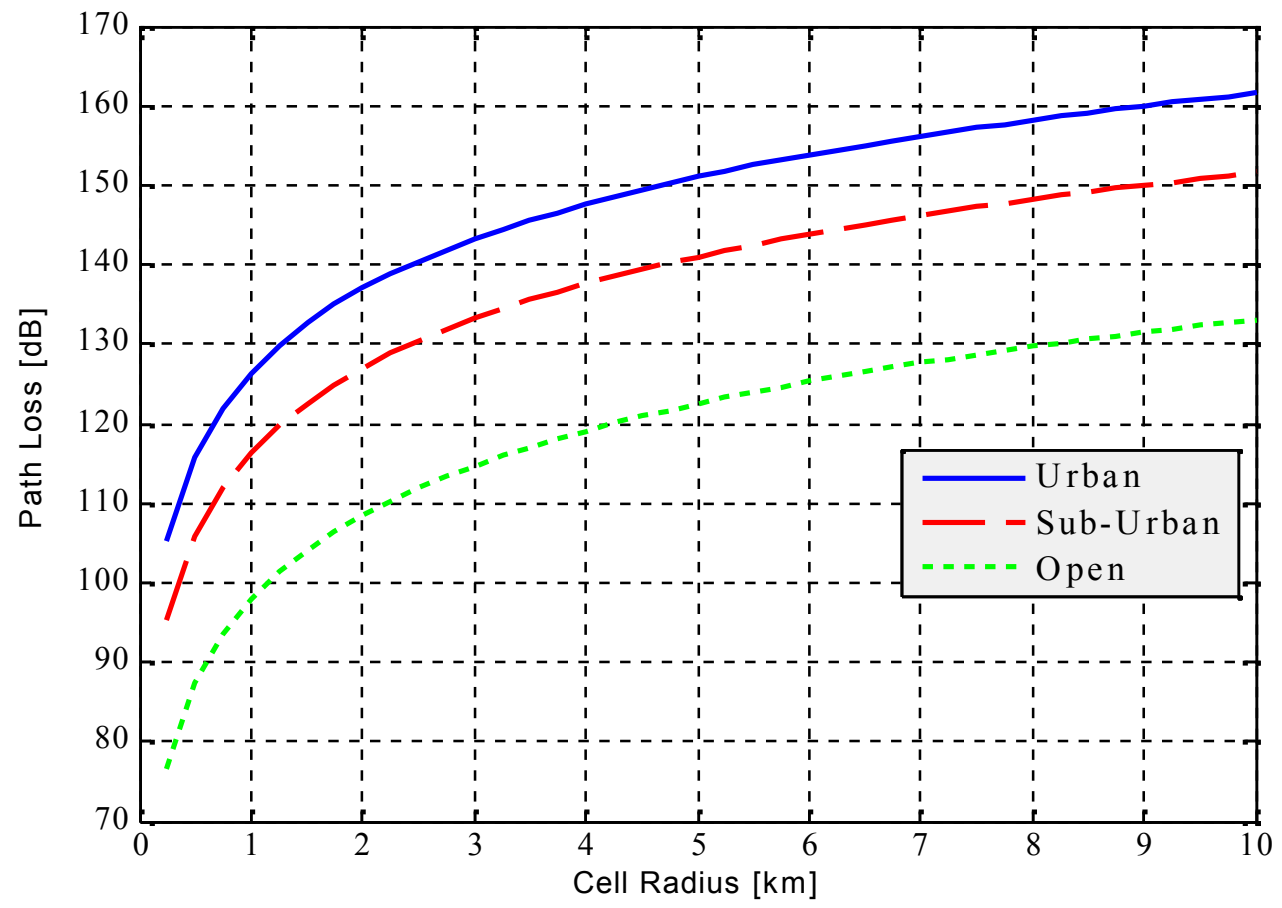

Figure 1: Path Loss as a Function of Cell Radius for Urban , Sub-Urban \& Open Area .at $f=900 \mathrm{MHz}$. $h(t)=30 \mathrm{~m} h(r)=1.5 \mathrm{~m}$

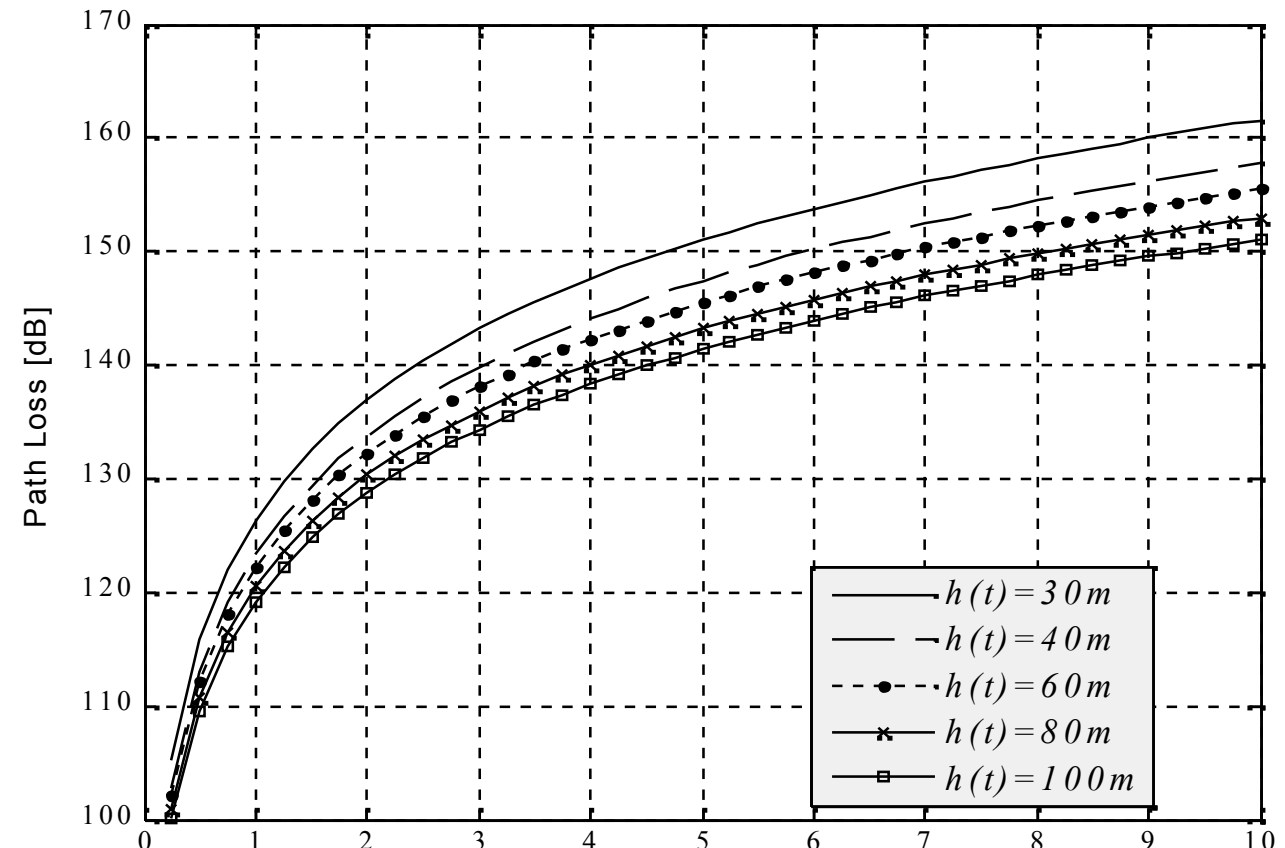


(c) Cost 231-Hata Model [8]. This model is developed which is an extended version of Hata model for frequencies of $1500 \mathrm{MHz}$ to $2000 \mathrm{MHz}$.

This model is applicable for GSM 1800-urban area.

$$
\begin{aligned}
\mathrm{Lpu}= & 46.3+33.9 \log _{10} \mathrm{f}-13.82 \log _{10} \mathrm{~h}(\mathrm{t})-\mathrm{a} \mathrm{h}(\mathrm{r}) \\
& +\left[44.9-6.55 \log _{10} \mathrm{~h}(\mathrm{t})\right] \log _{10} \mathrm{~d}+\mathrm{Cm}(\mathrm{dB})
\end{aligned}
$$

Where:

$\mathrm{Cm}=0 \mathrm{~dB}$ for medium city and suburban centers with moderate tree density.

\section{Path loss prediction for GSM}

Path loss determine the cell ranges. For GSM there are three cell ranges:

- Large cells, cell radius is $1 \mathrm{Km}$ and normally it exceeds $3 \mathrm{Km}$.

- Small cells, cell radius $1 \mathrm{Km} \rightarrow 3 \mathrm{Km}$.

Additional loss called indoor loss (penetration loss) which varies greatly depending on type of material, architecture (numbers of windows), floor within building, etc. [9].

- Microcells: of radius in the range of $200 \mathrm{~m}-300 \mathrm{~m}$.

The propagation in the above three cell sizes is determined by diffraction and scattering.

\section{Fading [4][9]}

A mobile radio signal envelope has a continuous variations. The signal level fluctuates continuously.

In mobile environment, the fading is of two types:

a- Small scale fading: Which results from rapid level fluctuation over a short period or travel distance $\left(\approx \frac{\lambda}{2}\right)$. The MS antenna $(1 \mathrm{~m} \rightarrow 5$ $\mathrm{m})$ is lower than surrounding objects, so several multipath signals arrive with various phases and amplitudes and at certain times 
almost cancel each other, deepest fades $(\approx 30 \mathrm{~dB})$. Small-scale fading is Rayleigh fading and only occurs when all waves are reflected Non Line of Sight (NLOS) and no wave is direct line of Sight (LOS), as shown in Figure 3.

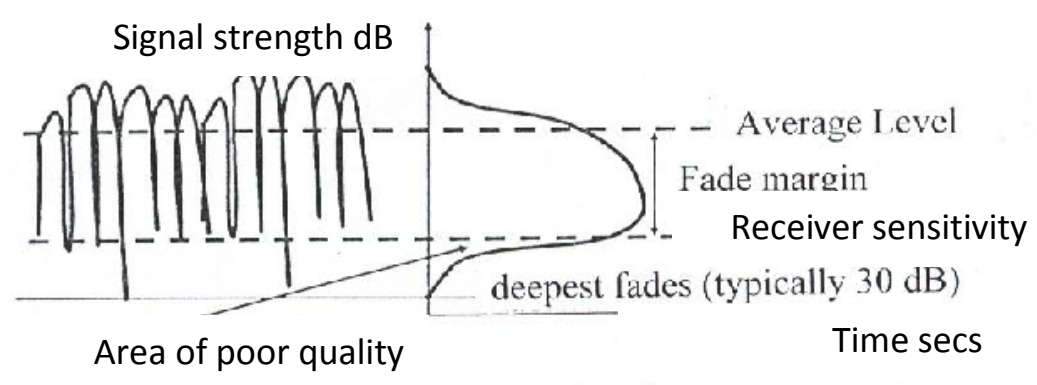

Figure 3: Small scale fading (Rayleigh fading) [9]

b- Log-Normal Fading: This fading is due to the terrain contours between the BTS and the MS. If the terrain is open area then the decrease of signal strength is due to distance, but normally there are obstructions (buildings, trees, etc.) which cause rapid variation of the signal. When the fading exceeds the minimum receives level will result in shadow areas. The remedy is to keep an addition fade margin on top of the minimum receiver level as in Figure 4 when predicating coverage. This margin is called Log-normal shadow margin and is typically in the range $2-5 \mathrm{~dB}$ with standard deviation in the range of

$4-8 \mathrm{~dB}$. For urban areas, GSM recommendation is a margin of $5 \mathrm{~dB}$ (comsidering $7 \mathrm{~dB}$-o asnothel fadination) to achieve $90 \%$ location

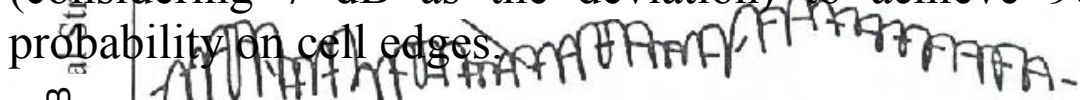

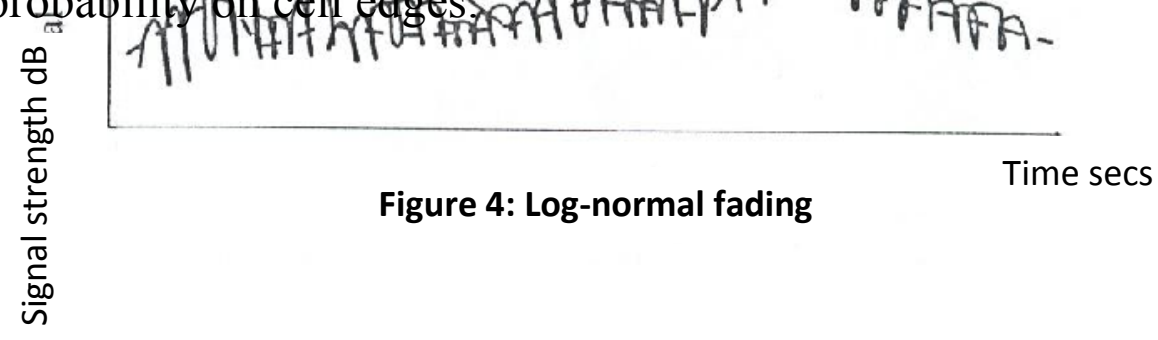




\section{Multipath Fading (Time Dispersion) [5] [6] [10]}

The mobile radio channel is dynamic due to multipath propagation. This has a strong negative impact on the bit error rate (BER) of any modulation techniques, causing the signal at the receives to distort or fad significantly as compared to Additive White Gaussian Noise (AWGN) channel.

Equalizers in GSM system compensate for intersymbol interference (ISI) created by multipath within time dispersive channel. In GSM equalizers can handle multipath within a delay spread of four bit periods $\mu \mathrm{sec})$ (path difference

of $4.5 \mathrm{~km})$.

Any multipath component arriving after $15 \mu$ sec will act as interference.

In GSM the carrier to interference $(\mathrm{C} / \mathrm{I})$ ratio is not less than $9 \mathrm{~dB}$. The same applies for carrier to multipath component (greater than 15 $\mu$ sec delar.

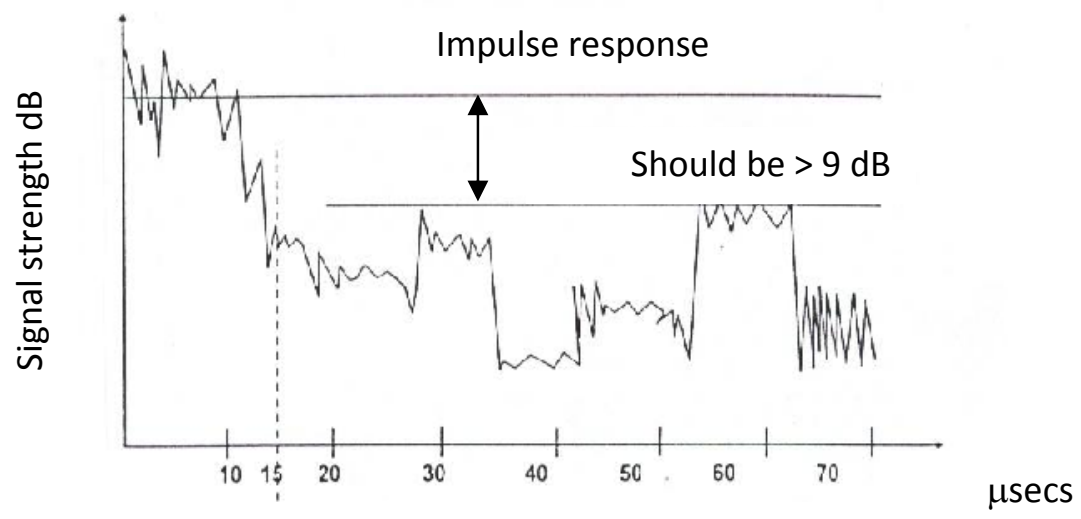

Figure 5: Time dispersion (Multipath). [10]

\section{Cell Architecture}


Figure (6) shows the basic cell architecture.

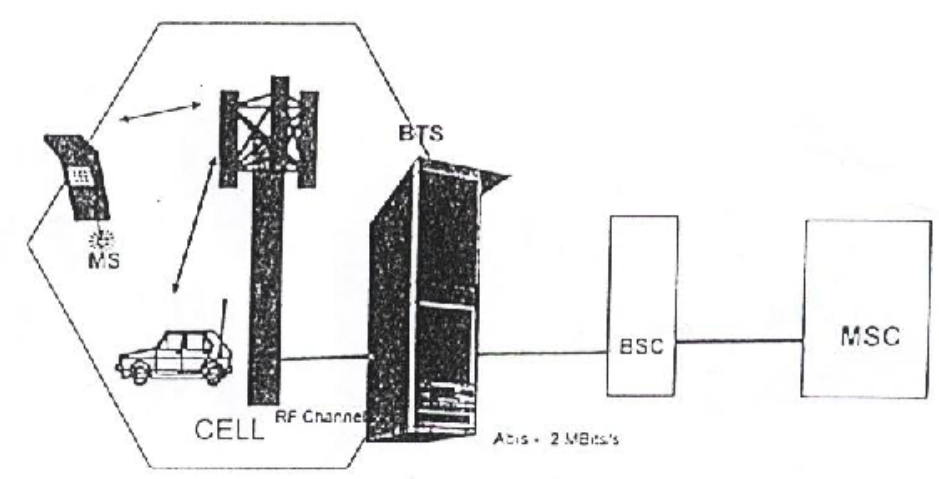

Figure 6: Cell Architecture:

BTS: Base Transceiver Station.

BSC: Base Station Controller.

For GSM 900, typical output power of MS and BTS are as in Table

Table 1: GSM 900 output power of BTS and MS [9]

\begin{tabular}{|r|r|}
\hline \multicolumn{2}{|c|}{ BTS } \\
\hline Class & $\begin{array}{r}\text { Max. Output- } \\
\text { Power }\end{array}$ \\
\hline
\end{tabular}

\begin{tabular}{|l|r|}
\hline \multicolumn{2}{|c|}{ MS } \\
\hline Class & $\begin{array}{r}\text { Max. Output- } \\
\text { Power }\end{array}$ \\
& \\
\hline
\end{tabular}




\begin{tabular}{|c|c|c|c|c|}
\hline 1 & $320 \mathrm{~W}(55 \mathrm{dBm})$ & 1 & $20 \mathrm{~W} \quad(43 \mathrm{dBm})$ & \multirow{2}{*}{$\begin{array}{c}\text { Vehicle } \\
\& \\
\text { Portable }\end{array}$} \\
\hline 2 & $160 \mathrm{~W}(52 \mathrm{dBm})$ & 2 & $8 \mathrm{~W} \quad(39 \mathrm{dBm})$ & \\
\hline 3 & $80 \mathrm{~W}(49 \mathrm{dBm})$ & 3 & $5 \mathrm{~W} \quad(37 \mathrm{dBm})$ & Hand held \\
\hline 4 & $40 \mathrm{~W} \quad(46 \mathrm{dBm})$ & 4 & $2 \mathrm{~W} \quad(33 \mathrm{dBm})$ & Hand held \\
\hline 5 & $20 \mathrm{~W} \quad(43 \mathrm{dBm})$ & 5 & $0.8 \mathrm{~W} \quad(\approx 29 \mathrm{dBm})$ & Hand held \\
\hline 6 & $10 \mathrm{~W}(40 \mathrm{dBm})$ & & & \\
\hline 7 & $5 \mathrm{~W} \quad(37 \mathrm{dBm})$ & & & \\
\hline 8 & $2.5 \mathrm{~W} \quad(34 \mathrm{dBm})$ & & & \\
\hline
\end{tabular}

\section{Power Budget Calculation}

The objective is to balance the uplink and down link. Since the MS and the BTs have different RF architecture, the receive signal sensitivity will be different. BTs power can be adjusted to balance the link. The power balance (uplink and down link) will also decide the cell range.

a- When the down link is greater than the uplink (limitation of the MS output power and BTs receivers sensitivity) resulting in the followings.

- Range of BTS > Range of MS.

- Call dropped on uplink after initiation of handover.

- Coverage area is smaller in reality than the prediction.

- This is the most frequent case.

b- When the uplink is greater than the down link.

- Range of MS > Range of BTS.

- No coverage problem from MS to BTS.

If the uplink $>$ down link, it is better than uplink $<$ down link. 


\section{Illustrative calculations}

a- Calculation of MS and BTS sensitivities:

MS Sensitivity $\left(\mathbf{S}_{\mathrm{MS}}\right)$ :

It is minimum signal level at the input that leads to the signal to noise

at the output, higher than a threshold $\mathrm{E}_{\mathrm{c}} / \mathrm{N}_{\mathrm{o}}$ related to the modulator performance [9].

$\mathrm{S}_{\mathrm{MS}}=10 \log _{10}(\mathrm{KTB})+\mathrm{E}_{\mathrm{c}} / \mathrm{N}_{\mathrm{o}}+\mathrm{NF}$

Where:

$\mathrm{K}=$ Boltzman's constant $\left(1.38 \times 10^{-23} \mathrm{~J} / \mathrm{K}^{\mathrm{o}}\right)$.

$\mathrm{T}=$ Ambient temperature $\left(300 \mathrm{~K}^{\mathrm{o}}\right)$.

$\mathrm{B}=$ Equivalent noise bandwidth $(200 \mathrm{KHz})$.

$\mathrm{E}_{\mathrm{c}} / \mathrm{N}_{\mathrm{o}}=$ Intrinsic characteristic of the modulator $(8 \mathrm{~dB})$.

$\mathrm{NF}=$ Noise figure of receiver $(10 \mathrm{~dB})$.

$\mathrm{S}_{\mathrm{MS}}=-120 \mathrm{dBm}+8 \mathrm{~dB}+10 \mathrm{~dB}=-102 \mathrm{dBm}$

BTS Sensitivity $\left(\mathbf{S}_{\mathrm{BTS}}\right)$ :

The same as for MS but NF $=8 \mathrm{~dB}$

$\mathrm{S}_{\mathrm{BTS}}=-104 \mathrm{dBm}$

b- Uplink Budget and Cell Range:

Transmitting End:

$\mathrm{EIRP}=\mathrm{P}_{\mathrm{MS}}+\mathrm{L}_{\mathrm{AFC}}+\mathrm{G}_{\mathrm{MS}}$

Where:

EIRP $=$ Effective isotropic radiated power.

$\mathrm{P}_{\mathrm{MS}}=$ Power output of MS. 
$\mathrm{L}_{\mathrm{AFC}}=$ Loss in antenna feeder / connector loss $(0 \mathrm{~dB})$.

$\mathrm{G}_{\mathrm{MS}}=$ Mobile antenna gain $(0 \mathrm{~dB})$.

\section{Receiving End:}

$\mathrm{R}_{\mathrm{x} \text { min.- level }}=\mathrm{EIRP}-\mathrm{L}_{\mathrm{PAB}}-\mathrm{I}_{\mathrm{DM}}-\mathrm{L}_{\mathrm{SM}}-\mathrm{L}_{\mathrm{ACC}}+\mathrm{G}_{\mathrm{BTS}}$

Where:

$\mathrm{R}_{\mathrm{x} \text { min-level }}=$ BTS sensitivity $(-104 \mathrm{dBm})$.

$\mathrm{L}_{\mathrm{PAB}}=$ Propagation loss $+3 \mathrm{~dB}$ (antenna / body loss).

$\mathrm{I}_{\mathrm{DM}}=$ Interference degradation margin $(3 \mathrm{~dB})$.

$\mathrm{L}_{\mathrm{SM}}=$ Log normal shadowing margin for $90 \%$ coverage area $(5$ dB).

$\mathrm{L}_{\mathrm{ACC}}=$ BTS antenna cable and connector $(0 \mathrm{~dB})$.

$\mathrm{G}_{\mathrm{BTS}}=$ BTS receiving antenna gain $(12 \mathrm{~dB})$.

Using equations (7) (8) and (9) it is possible to calculate the maximum affordable path loss in the uplink. The maximum affordable path loss when substitutes in Hata model will give the cell range (d) in the uplink, as given in equation (1). Adding penetration loss (15 dB as per GSM recommendation) to the path loss and a gain substitute in Hata model, this gives the indoor coverage range.

An illustrative exercise, using practical values:

Terrain $=$ urban area.

$\mathrm{P}_{\mathrm{MS}}=29 \mathrm{dBm}(0.8 \mathrm{~W})$.

MS antenna loss $=0 \mathrm{~dB}$

$\mathrm{G}_{\mathrm{MS}}$ antenna gain $=0 \mathrm{~dB}_{\mathrm{i}}$ ( $\mathrm{i}$ is for isotropic).

$\mathrm{h}(\mathrm{r})$ (mobile station antenna height) $=1.5 \mathrm{~m}$.

$\mathrm{G}_{\mathrm{BTS}}$ receiver antenna gain $=12 \mathrm{~dB}$.

$\mathrm{B}_{\mathrm{TS}}$ receiver to antenna cable loss $=4 \mathrm{~dB}$. 
$\mathrm{h}(\mathrm{t})$ base station antenna height $=30 \mathrm{~m}$.

Interference margin $=3 \mathrm{~dB}$.

Log normal margin $=5 \mathrm{~dB}$ (for $90 \%$ coverage area).

Indoor loss $15 \mathrm{~dB}$.

To calculate the maximum affordable path loss and cell range (d) for both outdoor and indoor:

- Uplink Budget and cell range (d)

Using equation (8)

$\mathrm{EIRP}=29-0-0=29 \mathrm{~dB}$

Using equation (9) below:

$$
\begin{aligned}
\mathrm{R}_{\mathrm{x} \text { min.-Level }}= & \mathrm{EIRP}-\mathrm{L}_{\mathrm{PAB}}-\mathrm{I}_{\mathrm{DM}}-\mathrm{L}_{\mathrm{SM}}-\mathrm{L}_{\mathrm{ACC}}+\mathrm{G}_{\mathrm{BTS}} \\
& -104=29-\mathrm{L}_{\text {urban }}-3-4-5+12
\end{aligned}
$$

$\mathrm{Lpu}=133-3($ antenna $/$ body loss $)=130 \mathrm{~dB}$

Using eq. (1), results:

$130=126.4+35.2 \log _{10} \mathrm{~d}$

$\mathrm{d}=1.26 \mathrm{~km}$ for outdoor.

And

$130=126.4+15+35.2 \log _{10} d$

$\mathrm{d}=0.47 \mathrm{~km}$ for indoor.

- Down Link Budget and cell range (d)

Transmitting End:

$\mathrm{EIRP}=\mathrm{P}_{\mathrm{BTS}}-\mathrm{L}_{\mathrm{CFI}}-\mathrm{L}_{\mathrm{AFC}}+\mathrm{G}_{\mathrm{BTS}}$

Where:

$\mathrm{P}_{\mathrm{BTS}}=$ Output power of BTS.

$\mathrm{L}_{\mathrm{CFI}}=$ Combiner / filter / isolator loss $(4 \mathrm{~dB})$. 
$\mathrm{L}_{\mathrm{AFC}}=\mathrm{BTS}$ transmitter antenna feeder / connector loss $(2 \mathrm{~dB})$.

$\mathrm{G}_{\mathrm{BTS}}=$ BTS transmitter gain $\left(8 \mathrm{~dB}_{\mathrm{i}}\right)$.

Receiving End:

$\mathrm{R}_{\mathrm{xMin}-\mathrm{Level}}=\mathrm{EIRP}-\mathrm{L}_{\mathrm{PAB}}-\mathrm{I}_{\mathrm{DM}}-\mathrm{L}_{\mathrm{SM}}-\mathrm{L}_{\mathrm{MCC}}+\mathrm{G}_{\mathrm{MS}}$

Where:

$\mathrm{R}_{\mathrm{xMin}-\text { Level }}=$ MS Senitivity $(-102 \mathrm{dBm})$

$\mathrm{L}_{\mathrm{PAB}}=$ Propagation loss $+3 \mathrm{~dB}$ antenna (body loss).

$\mathrm{I}_{\mathrm{DM}}=$ Interference degradation margin $(3 \mathrm{~dB})$.

$\mathrm{L}_{\mathrm{SM}}=\log$ normal shadowing margin for $90 \%$ coverage area $(5$ $\mathrm{dB})$.

$\mathrm{L}_{\mathrm{MCC}}=\mathrm{MS}$ antenna cable and connector loss $(0 \mathrm{~dB})$.

$\mathrm{G}_{\mathrm{MS}}=$ MS antenna gain.

Since propagation loss is the same in both uplink and down link, substituting

the maximum affordable path loss value calculated in the uplink budget in equation (11) to obtain the EIRP $-102=$ EIRP $-130-3-$ $5+0$.

$\therefore \mathrm{EIRP}=36 \mathrm{dBm}$

Using equation (10).

$36=\mathrm{P}_{\text {BTS }}-4-2+8$

$\mathrm{P}_{\mathrm{BTS}}=34 \mathrm{dBm}$

In the present study case there is an imbalance of $5 \mathrm{~dB}$ between uplink and down link. This can be compensated by increasing the BTS power by $5 \mathrm{~dB}$.

Also other practical areas of imbalance (diversity gain of the BTS receiver

(4-6 dB) and hence will make the uplink more strong. Therefore, 
adding 4-6 $\mathrm{dB}$ to the BTS output power, so that balance is maintained in the down link also.

\section{Conclusions}

There are many essential issues to be considered.

- The choice of propagation model suitable for the terrain profile of the cell.

- Time dispersion (multipath) is a major issue in live network and can be reduced by cell site location and sectorized antenna's.

For site location: is to identify the potential reflector in the predicated cell area, location of sites for BTS near reflector which will bring the reflection within the tolerable delay spread of 15 $\mu$ sec. which can dealt with by the modulator.

For antenna's: using sectorized cell configuration with directional antenna pointing away from the reflector, also antenna front to back ratio is a very critical parameter.

- To achieve a balance between uplink and down link receive signal since MS and BTS have different RF architecture and different sensitivities. Since RF link balance depends on:

BTS transmitter power, BTS combiner loss and BTS receiver diversity gain.

- RF link balance calculation decides the cell coverage range.

\section{References}

1. M. R. Karim \& M. Sarraf, "W-CDMA and cdma 2000" for $3 \mathrm{G}$ Mobile Network", McGraw-Hill Telecom. Professionals pp. 332334, 2002.

2. Lucent Technologies, "Personal Communication Services", CDMA RF Engineering", Internal Publication, 1998.

3. Lucent Technologies, "AUTOPLEX Cellular telecommunication System, System 1000, CDMA RF Engineering Guide Lines", Internal Publication, 1998.

4. D. P. Agrawal \& Q. Zeng, "Introduction to Wireless and Mobile Systems", Thomson Books / Cole, Chapter 3, 2003. 
5. T. S. Rappaport, "Wireless Communications", 2nd Edition, Prentice Hall, Chapter 4, 2002.

6. B. H. Walke, "Mobile Radio Networks", and Edition, John Wiley and Sons, pp. 44-46, 2002.

7. K. Pahlavan and A. H. Levesque, "Wireless Information Networks", John Wiley and Sons, pp. 74-82, 1995.

8. European Cooperation in the Field of Scientific and Technical Research EURO-COST 231 "Urban Transmission Loss Models for Mobile Radio in the 900 and $1800 \mathrm{MHz}$ Bands", Revision 2. The Hague, September 1991.

9. Asiacell Handbook, www.asiacell.com chapter 4, pp. 25.

10. Agilent Technologies, pp. 46, 1999. 